\title{
Numerical analysis of glass-FRP post-tensioned beams - Review and assessment
}

\author{
Chiara Bedon ${ }^{\mathrm{a}, *}$, Christian Louter ${ }^{\mathrm{b}}$ \\ ${ }^{a}$ Department of Engineering and Architecture, University of Trieste, Trieste, Italy \\ ${ }^{\mathrm{b}}$ Department of Architectural Engineering and Technology, Faculty of Architecture and the Built Environment, Delft University of Technology, The Netherlands
}

\section{A R T I C L E I N F O}

\section{Article history:}

Received 15 January 2017

Revised 27 April 2017

Accepted 26 June 2017

Available online 27 June 2017

\section{Keywords:}

Structural glass

Laminated glass

Fibre-Reinforced-Polymer (FRP) composites

Adhesive joints

Glass-FRP hybrid beams

Post-tensioning

Experimental tests

Finite-Element numerical modelling

\begin{abstract}
A B S T R A C T
Architectural trends to include transparency in structural systems lead to the implementation, in the last decades, of structural glass load-bearing components able to substitute traditional construction materials like timber, steel, concrete.

In this paper, the structural bending performance of post-tensioned, glass-FRP hybrid beams is evaluated by means of advanced Finite-Element (FE) numerical analyses. To this aim, a concise recapitulation of existing research on several typologies of glass-FRP hybrid beams is first provided. Based on earlier experimental and preliminary FE research outcomes, further detailed discussion is then proposed for the specific concept of glass-FRP post-tensioned glass beams. FE parametric simulations for quasistatic bending loading configuration and room temperature are compared for such systems, typically including a laminated glass (LG) cross-section and an adhesively connected, post-tensioning FRP tendon. As shown, several aspects should be properly taken into account when investigating the overall performance of these systems, as far as both their elastic and post-cracked performance are highly sensitive to various mechanical and geometrical input parameters. A sensitivity FE study is hence presented, aiming to better explore their typical performance.
\end{abstract}

(c) 2017 Elsevier Ltd. All rights reserved.

\section{Introduction}

Architectural trends to include transparency in structural systems lead to the implementation, in the last decades, of structural glass load-bearing components able to substitute traditional construction materials like timber, steel, concrete. In most cases, aiming to further enhance the structural performance of a typically tensile brittle material, research studies and design projects have been in fact focused on composite glass systems. Especially for beam structures, composite glass beam systems are explored in which glass is combined with metal, timber or Fibre Reinforced Polymer (FRP) composites [1,2].

For glass-FRP composite beam solutions in specific, it is noted that these are typically obtained by adhesively bonding a monolithic or laminated glass (LG) section (namely representing the web of the so assembled systems) with one or more FRP sections, consisting in various FRP solutions as well as specific geometrical/ mechanical properties [3-9].

In this paper, based on $[10,11]$, a specific typology of the recalled glass-FRP solutions is selected, being composed of an LG

\footnotetext{
* Corresponding author.

E-mail addresses: bedon@dicar.units.it, chiara.bedon@dia.units.it (C. Bedon).
}

cross-section with an adhesively bonded bottom tendon consisting of a Carbon Fibre Reinforced Polymer (CFRP) solid section.

As shown, compared to other existing glass-FRP hybrid solutions, the CFRP reinforcement has a double beneficial effect, since it provides additional tensile reinforcement to glass but especially a relevant post-tensioning contribution to the resisting crosssection. As far as the bending performance of such beams has to be optimized, however, several geometrical and mechanical aspects should be properly taken into account and calibrated. To this aim, based on past experimental and preliminary FE studies for the selected hybrid solution [10,11], an FE parametric investigation is carried out in ABAQUS [12] with full 3D solid models, aiming to provide an insight on the potential and criticalities of these rather innovative structural systems.

\section{State-of-the-art on glass-FRP beam research}

\subsection{Experimental research}

So far, several researchers experimentally investigated the structural performance of glass-FRP beams characterized by various geometrical features. The common aspect of all the experimental studies available in literature is basically given by hybrid beams 
in which the web consists of a glass pane that is solicited about its major axis, while FRP reinforcements can take several forms.

Despite the variability of possible solutions of glass-FRP beams bending about their major axis, the existing research projects are here distinguished in two major groups, namely (a) reinforced or (b) post-tensioned glass-FRP beams.

Within the group (a) of glass-FRP beams, the bending stiffness and resistance of a traditional monolithic or LG section is generally enhanced via adhesively bonded FRP profiles or embedded rods.

CFRP reinforced glass beams have been first investigated and applied by Palumbo et al. [3]. The beams consisted of a laminated annealed float glass web and an CFRP section which was adhesively bonded at the tensile edge. The concept has been experimentally investigated on scaled beam models and has then been applied in a roof covering for the 'Loggia de Vicari' in Italy. Glass Fibre Reinforced Polymer (GFRP) pultruded profiles have been used in the research project of Correia et al. [4] and Valarinho et al. [5] to act as flanges for I-shaped composite beams. In this respect, the GFRP flanges both act as lateral stiffeners and post-cracking reinforcement In their experimental investigation, the typical I-beam consisted of an annealed glass web and solid/angular GFRP pultruded profiles adhesively connected to glass. The main difference in such specimens was represented by the shape and size of GFRP profiles, by the total span of the beams and by the adhesive connection (type and thickness of adhesive).

A different FRP reinforced glass beam design concept has been explored by Louter et al. [6], that focused on the structural performance of glass beams with CFRP or GFRP cords (both round or flat rods) physically embedded within the interlayer of a traditional laminated glass panel. Speranzini and Agnetti [7] investigated the structural performance of composite sections in which C-shaped pultruded GFRP profiles were used at the bottom of the beam. Speranzini and Neri [8] explored then a further concept of glassFRP composite beams. Their typical beam configuration consisted in alternating float glass sheets with vertical layers of GFRP, connected to the adjacent glass panels via a two-component epoxy resin.

In terms of (b) post-tensioned glass-FRP beams, few experimental studies only have been carried out. Louter et al. [10], in particular, explored the efficiency of a further design concept, in which a traditional LG beam composed of three annealed glass layers and SentryGlas ${ }^{\circledR}(\mathrm{SG})$ foils was reinforced with a pre-stressed CFRP tendon adhesively connected at the bottom edge of the resisting crosssection, see Fig. 1.

Together with the additional bending stiffness and strength implicitly provided to the LG section by the CFRP tendon, further enhancement of the expected bending performance of the so assembled system was given by the introduction of an initial pre-stressing force $P_{0}=13.6 \mathrm{kN}$ in the tendon itself. As such, as also shown in [10], the glass-CFRP beam proved to offer high postcracked residual resistance and ductility, compared to the reference LG section.

\subsection{Finite-Element numerical research on hybrid glass beams}

Finite-Element modelling generally represents an efficient tool to assess the overall performance of several structural systems. In doing so, depending on the specific system object of investigation, key aspects are typically represented by the correct mechanical calibration of materials, as well as by the implementation of a realistic reciprocal interaction between the system components, etc. This is especially true in the case FE simulations are aimed to take into account damage propagation and possible failure mechanisms.

In terms of FE simulation of hybrid glass beams, with careful consideration of the post-fracture response of these systems, sev- eral research efforts can be found in literature. Most of them include the structural analysis of steel-glass reinforced composite beams, namely obtained by adhesively bonding a stainless steel tendon or reinforcement section and a traditional beam, composed both of monolithic or multilayer LG. Louter and Nielsen [13] first and Bedon and Louter [14] later, for example, explored the bending performance of LG beams with a steel tendon bonded at their tensile edge. The difference between [13] and [14], given the same beam specimens, was basically represented by the FE modelling assumptions for the description of tensile cracking of glass and thus by the corresponding solving approach with the ABAQUS computer software, namely involving - in the first case - a selfmade material user subroutine and - in the second case - the "brittle cracking" damage model available in ABAQUS for ceramics. The research topic and FE modelling approach presented in [14] was then also explored in [15], giving evidence of structural effects and possible benefits on the overall performance of the same composite beams, due to initial pre-stressing forces applied in the steel tendon.

In accordance with [13] and related FE assumptions, a mostly similar steel-glass design concept was analysed in [16], while Martens et al. [17] further extended the modelling approach proposed in [14], aiming to assess the structural performance of statically indeterminate steel-glass reinforced beams.

Following [11,14,17], in [18] the post-cracked flexural performance of timber-glass hybrid beams was numerically explored and compared to corresponding full-scale experimental results.

LG beams with un-bonded, mechanically anchored posttensioning steel tendons have been finally investigated in [19], via efficient FE models able to take into account the mechanical behaviour of each beam component, as well as the possible tendon-to-glass interaction during bending. Differing from [14], the "concrete damaged plasticity" model originally implemented in ABAQUS for reinforced concrete structures was used, with appropriate mechanical calibration. Careful attention was paid for the pre-stressing stage as well as for the implementation of appropriate mechanical connectors able to describe any possible physical contact and interaction between the steel tendons and the $\mathrm{LG}$ beam in bending.

While several FE studies are available for steel-glass reinforced and post-tensioned beams, few FE efforts have been dedicated, on the other hand, to the analysis of the post-cracked performance of glass-FRP hybrid solutions. In Neto et al. [20], for example, the structural behaviour of glass-GFRP beams tested in [4] was numerically investigated. As an alternative to the smeared damage model proposed in $[11,14]$, the FE investigation was carried out based on a Discrete Strong Discontinuity Approach (DSDA) able to account for the tensile brittle nature of glass. In [11], as a further extension of [14], a preliminary assessment of the experimental test results recalled in Fig. 1 for post-tensioned glass-CFRP beams was carried out. Compared to [14], additional attention was spent in the FE implementation of such models, in order to properly describe the post-tensioning phase as well as the related effects on each beam component. The FE results obtained from a reference numerical model (labelled as "M0", in the following sections) generally highlighted the potential of the basic modelling assumptions, as well as the rather close correlation with the corresponding test results (see for example Fig. 2).

As also experimentally observed for the same beam typology, in particular, the overall FE performance of glass-CFRP post-tensioned beams presented in $[10,11]$ was found to be associated to four specific phases, i.e. labeled as A, B, C and D in Fig. 2(a). As far as the beam specimens proved to offer interesting bending potential up to a maximum deflection of $\approx 25 \mathrm{~mm}(\approx / 60$ the total span), the first stage of their bending response, up to point $A$, was basically governed by the linear elastic stiffness of the fully 


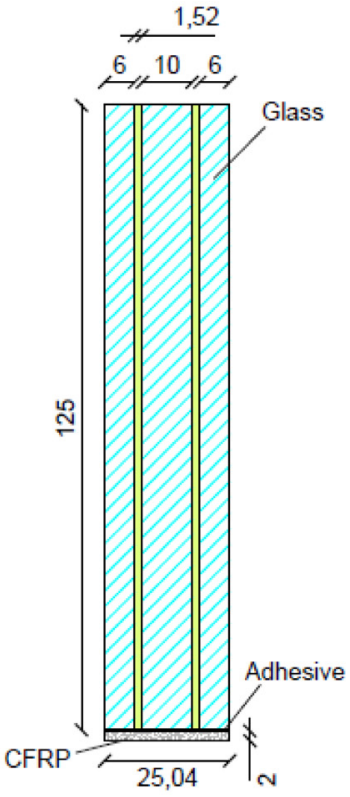

(a)

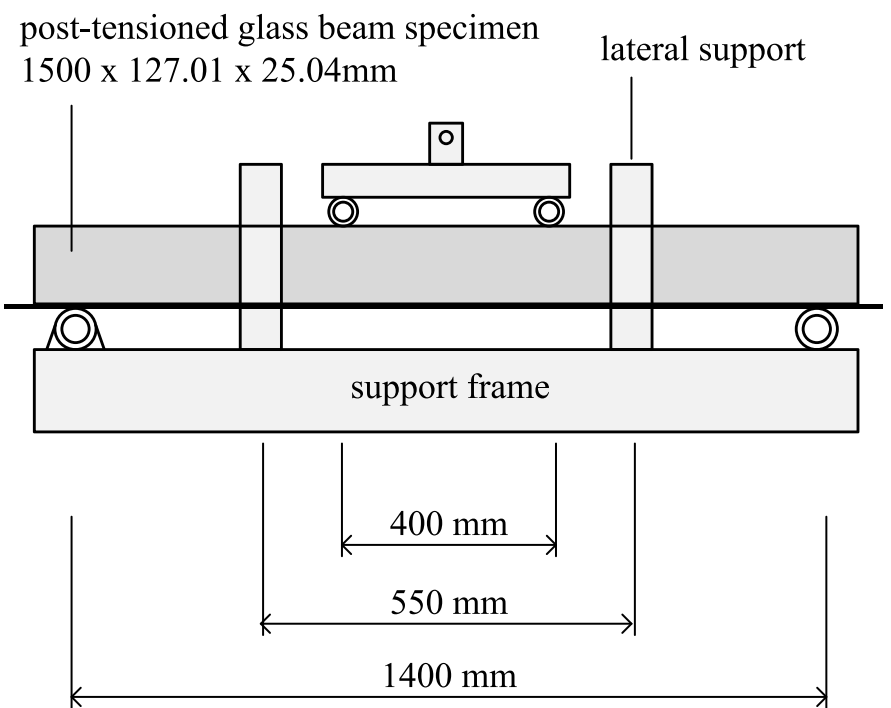

(b)

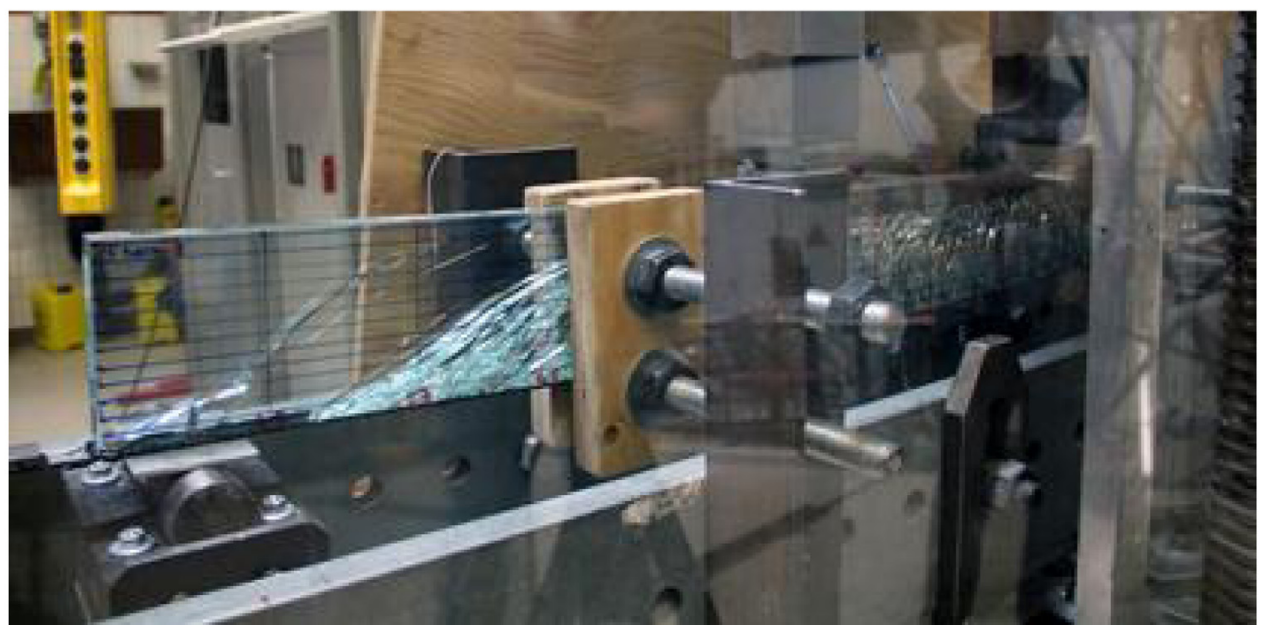

(c)

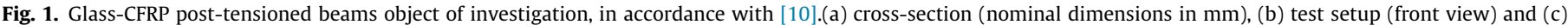
typical distribution of cracks in glass at collapse.

collaborating, composite post-tensioned section. As far as the imposed vertical displacements representative of the experimental bending loads provided a maximum tensile stress at the bottom edge of glass able to exceed the nominal resistance of the material, the load-deflection curve exhibits an abrupt jump and a marked variation of slope, compared to the uncracked stage, see point $A$ of Fig. 2(a). Following the first cracking occurrence, the opening of a large number of small cracks in glass - mainly located in the central part of the beam - further propagates (point B, Fig. 2(a)). The subsequent occurrence of some major cracks towards the beam ends manifests in the form of a partial numerical instability for the so predicted load-deflection relationship, i.e. due to consistent release of damage energy (see point C, Fig. 2(a)). The reinforced glass beam can be still able to provide further residual resistance, with almost constant post-cracked stiffness, up to the expected experimental failure deflection (point D, Fig. 2(a)).

In this paper, based on [11], the same FE modelling approach is recalled and further extended, aiming to provide - via a parametric study - a better insight on the structural performance of that specific structural typology.

\section{FE analysis of glass-FRP post-tensioned beams}

\subsection{General FE modelling approach}

In accordance with Louter et al. [10] and Bedon and Louter [11], the reference M0 model was implemented and calibrated aiming to explore the bending performance of a test specimen with LG section depicted in Fig. 1.

The reference cross-section consisted of annealed glass panels and SG foils, plus a $t_{C F R P}=2 \mathrm{~mm}$ thick CFRP tendon, joined to the LG section by means of $\mathrm{a} \approx 0.1 \mathrm{~mm}$ thick two-component epoxy (EP) adhesive joint (3 M DP490 type, see [21]). For the tendon, an CFRP solid section with $E_{F R P}=135 \mathrm{GPa}$ the nominal tensile modulus, $\sigma_{F R P}=2550 \mathrm{MPa}$ the tensile resistance and $\varepsilon_{F R P}=1.7 \%$ the elongation at fracture, as given by the manufacturer [22], was used. 


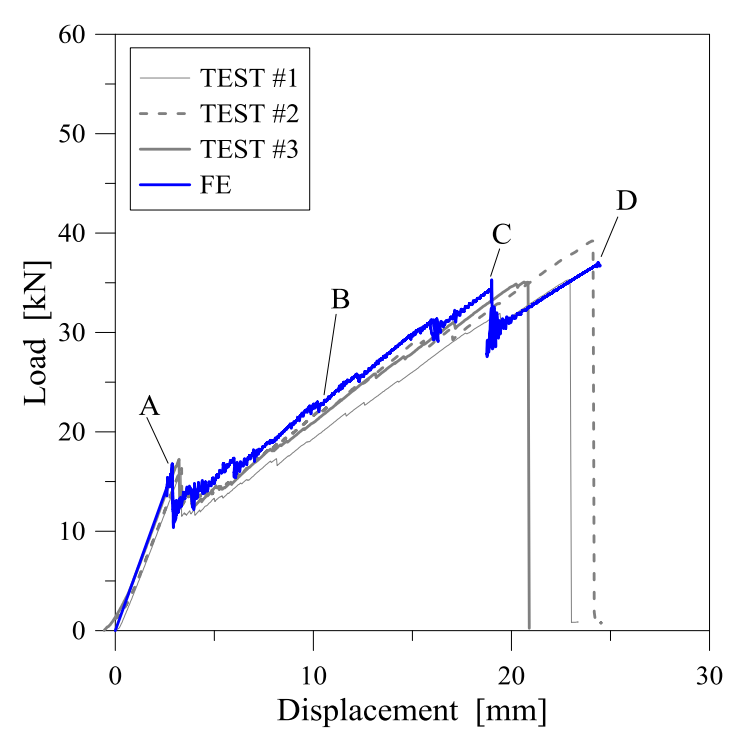

(a)

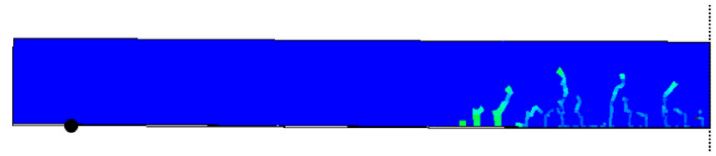

(b) $u_{\max }=15 \mathrm{~mm}$, front view

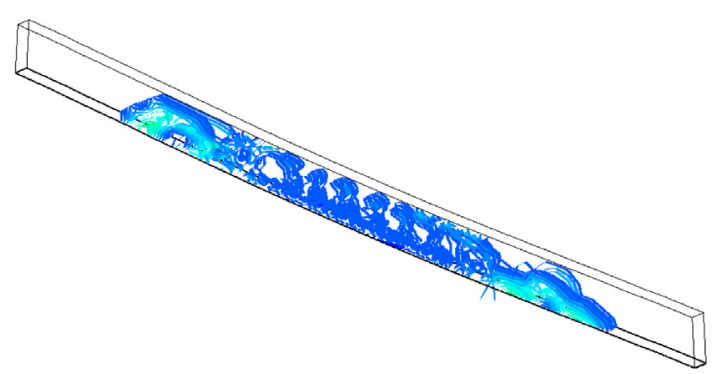

(c) $u_{\max }=25 \mathrm{~mm}$, axonometry

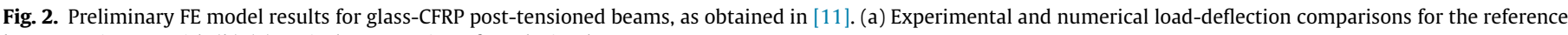
beam specimens, with (b)-(c) typical propagation of cracks in glass.

Based on the available experimental and FE preliminary results partly recalled in Section 2 and Figs. 1 and 2, a sensitivity FE study is presented in this paper for the same post-tensioned glass-CFRP beam concept.

The full FE exploratory investigation was performed via geometrically and mechanically refined, full 3D solid FE models implemented in the ABAQUS computer software [12], by giving careful attention to several aspects. Most of them include the mechanical calibration of the constitutive laws for the materials (CFRP, glass, SG, adhesive), the implementation of appropriate mechanical interactions between the hybrid systems object of analysis as well as the correct FE description of the loading phases, such as (I) the pre-stressing phase for the CFRP tendon, (II) the subsequent post-tensioning stage for the full composite assembly and (III) the bending step. Major assumptions considered for the typical FE model are summarized in the following sections.

\subsubsection{Materials}

Calibration of constitutive laws and damage models for each beam component was based on past literature contributions. Following [11], in particular, careful attention was paid to a realistic simulation of fracture and damage propagation in each beam components, namely tensile cracking of glass, tensile failure in the CFRP tendon or collapse of the adhesive joint.

At this stage, possible creep and viscous phenomena as well as debonding at the glass-to-SG or glass-to-adhesive interfaces were not taken into account, being the presented FE simulations reliable for the bending performance assessment of hybrid glass beams under room temperature and monotonic loads, assuming a rigid connection between the various components. It is also expected, in this regard, that the actual research investigation could be further extended, so that additional configurations (i.e. cyclic loading, temperature variations, as well as loading rate effects in general) could be also accounted on the overall structural performance of the explored beam typology.

3.1.1.1. Annealed glass. For annealed glass, in accordance with [23], the nominal value for the characteristic tensile strength $\sigma_{t k}=45 \mathrm{MPa}$ was taken into account. An homogeneous, linear elastic, isotropic material was defined, with nominal values for the modulus of elasticity ( $E_{\text {glass }}=70 \mathrm{GPa}$ ) and the Poisson ratio $\left(v_{\text {glass }}=0.23\right)$, see [23].

The brittle cracking damage model with its brittle shear and brittle failure sub-options was then used [12], to account for cracks propagation in each glass layer.

Given a tensile brittle material like glass, concrete, rocks or ceramics in general, the key input parameters of this damage model, being the approach based on a simple Rankine failure criterion, are represented by the tensile strength of glass $\sigma_{t k}$ and its fracture energy $G_{f}$.

In the current FE study, the input parameters for the damage model were derived from past literature contributions and recent applications to structural glass systems, see for example $[11,14]$. Given the nominal characteristic value $\left(\sigma_{t k}=45 \mathrm{MPa}\right)$, for the fracture energy a reference value $G_{f}=3 \mathrm{~J} / \mathrm{m}^{2}$ was taken into account.

Regarding the post-cracked behaviour of glass and the related brittle shear and brittle failure sub-options, through the FE analyses the damage evolution in glass was taken into account in the form of a variable cracked shear modulus $G_{c, \text { glass }}$, being this latter estimated as a fraction of the uncracked modulus $G_{\text {glass }}$ :

$G_{c, \text { glass }}=\beta\left(\varepsilon_{n n}^{c k}\right) \cdot G_{\text {glass }}$,

with

$0 \leqslant \beta\left(\varepsilon_{n n}^{c k}\right)=\left(1-\frac{\varepsilon_{n n}^{c k}}{\varepsilon_{\max }^{c k}}\right)^{p} \leqslant 1$

the shear retention factor.

In Eqs. (1) and (2), $\varepsilon_{n n}^{c k}$ and $\varepsilon_{\max }^{c k}$ represent the actual and ultimate crack opening strains respectively, while the parameter $p=5$ was derived from earlier calibration [11,14].

Following Eq. (2), the non-constant value of $\beta$ depends on the crack opening strain, being representative of complete loss of aggregate interlock $(\beta=0)$ or fully uncracked stage $(\beta=1)$ respectively for a given mesh element. As far as Eqs. (1) and (2) govern the damage propagation in glass, the physical displacement representative for a given mesh element was taken into account via the brittle failure sub-option, where the ultimate displacement for cracked elements was set equal to: 
$u_{c k}=\frac{2 G_{f}}{\sigma_{t k}}$

3.1.1.2. CFRP, SentryGlas ${ }^{\circledR}$ and epoxy adhesive. Once an appropriate description for possible tensile cracking of glass was taken into account, simplified but realistic assumptions were considered for the mechanical calibration of the other constituent materials, namely the CFRP tendon, the SG foils and the epoxy adhesive joint.

In doing so, reference mechanical properties available in literature from past experimental studies or FE investigations as well as product technical data sheets were considered.

Based on Table 1, the elastic modulus of CFRP was set equal to $E_{\text {CFRP }}=135 \mathrm{GPa}$, with $v_{\text {CFRP }}=0.3$ the Poisson ratio. For the tendon, a linear elastic constitutive law was then taken into account. Differing from glass, due to the typically high tensile resistance of CFRP, no damage material models were in fact implemented to describe possible failure mechanisms. The evolution of maximum stresses in the tendon itself, however, was in any case continuously monitored through each simulation, aiming to avoid the exceedance of the nominal tensile resistance. At the same time, a reference ultimate strain was considered, being $\varepsilon_{u}=1.7 \%$ the nominal value at failure.

In terms of SG interlayer foils, in accordance with past literature research projects, an equivalent constitutive law was used to take into account the viscoelastic behaviour. Based on the experimental test results provided in $[10,24]$, an elasto-plastic stress-strain relationship was used, while the Poisson coefficient was set equal to $v_{S G}=0.49$. Beside the typical sensitivity and degradation of interlayer mechanical properties to time loading and temperature, in this regard, an almost null effect on the obtained FE results is expected to derive from the assumed constitutive law, for the examined beam typology under in-plane bending loads. It is clear, however, that an extended FE study of the same structural systems under variable loading ratios and ambient configurations should take into account a more detailed mechanical description of SG foils as well as adhesive interfaces, so that failure phenomena could be also described.

For the adhesive layer (3 M Scotch-Weld DP490 type [21]), finally, a linear elastic constitutive law was implemented in ABAQUS, with $E_{a d h}=660 \mathrm{MPa}$ and $v_{a d h}=0.38$ the modulus of elasticity and Poisson ratio respectively, as experimentally obtained in [25]. This latter assumption for the mechanical behaviour of adhesive was found to be reasonable, for the adhesive type of interest considered in the actual research study. In accordance with [25], the experimental response of 3 M DP490 epoxy specimens was found in fact to be almost linear up to failure.

\subsection{FE model concept and assembly}

The typical FE model consisted of 3D solid elements (8-node, brick elements (C3D8R type) available in the ABAQUS library were used) for (i) the laminated glass beam, (ii) the CFRP tendon and (iii) the adhesive layer.

Nominal dimensions were considered for all the FE model components, in accordance with Fig. 1.

Table 1

Mechanical properties of the CFRP tendon, in accordance with [22]

\begin{tabular}{lll}
\hline Property & Unit & Nominal value \\
\hline Density & $\mathrm{kg} / \mathrm{m}^{3}$ & 1600 \\
Tensile modulus & $\mathrm{GPa}$ & 135 \\
Tensile strength & $\mathrm{MPa}$ & 2550 \\
Compressive strength & $\mathrm{MPa}$ & 1600 \\
Elongation at fracture & $\%$ & 1.7 \\
\hline
\end{tabular}

Aiming to minimize the computational cost of simulations and ensure the accuracy of results, two major meshing approaches were taken into account for each beam component, and specifically a free meshing technique for the LG beam, combined with a regular mesh pattern for the CFRP tendon and the adhesive joint. In the first case, following [11], the average size of the brick elements was set in the range comprised between $1.5 \mathrm{~mm}$ and $30 \mathrm{~mm}$ (with dense mesh pattern at the tensile edge of the beam, see Fig. 3), in order to properly capture the tensile cracking phenomena in the glass layers when subjected to in-plane bending deformations, as well as to preserve the computational efficiency of the FE model.

The average mesh size for brick elements composing the CFRP tendon and the adhesive joint was set equal to $10 \mathrm{~mm}$, including two solid elements in the thickness of each layer.

The full FE assembly finally consisted of $\approx 140,000$ brick elements and $\approx 60,000$ DOFs (degrees of freedom).

Assuming a rigid connection at the interface between the glass layers and the adjacent SG foils, as well as the LG-to-adhesive interface, careful consideration was paid for the FE implementation of mechanical interactions and loading phases for the full assembly.

The typical simulation consisted, in fact, in a combination of three subsequent quasi-static steps carried out both in ABAQUS/ Standard and ABAQUS/Explicit [12], and namely represented by (see also Fig. 4):

(I) pre-stressing of the CFRP alone;

(II) release of the CFRP tendon \& glass-to-CFRP adhesive bonding phase;

(III) bending simulation of the full glass-CFRP assembly.

For each phase of the typical FE analysis, i.e. (I)-(III) phases, an appropriate combination of additional mechanical interactions, imposed loads/displacements and assigned nodal boundary conditions was also taken into account.

The final result was in fact to ensure the correct FE description of the post-tensioning stage alone and its effects on the fully glassCFRP composite assembly, before the in-plane bending simulation would be carried out for a comparative investigation of the examined beam typology.

\subsubsection{Pre-stressing of the CFRP tendon}

The pre-stressing phase was first numerically reproduced in the form of a static incremental analysis (ABAQUS/Standard). At this stage, the average experimental value of the imposed initial pretensioning force $P_{0}$ was assigned to the CFRP section only $\left(A_{C F R P}\right)$, in the form of an equivalent longitudinal displacement (Fig. 4, phase I). No mechanical interaction was implemented at the interface between the CFRP tendon (top face) and the upper adhesive joint (bottom face), hence allowing the CFRP tendon to axially deform and to slide freely.

\subsubsection{Post-tensioning of the $L G$ section}

Once attained the desired level of initial prestress $P_{0}$ in the CFRP tendon, the release $\&$ adhesive bonding stage was reproduced in a second static incremental step (Fig. 4, phase II).

Simple supports were introduced at the CFRP tendon ends, in accordance with the test setup proposed in Fig. 1 (i.e. with $50 \mathrm{~mm}$ the distance of beam supports from the tendon ends). A surface-to-surface, ideally rigid contact interaction was also assigned at the interface between the CFRP tendon (top face) and the adhesive joint (bottom face).

Assuming a fully rigid connection (i.e. null relative displacements and rotations among the interested mesh nodes of the steel and adhesive solid elements), in particular, the primary effect of this FE assumption is that the CFRP tendon, once released, can 


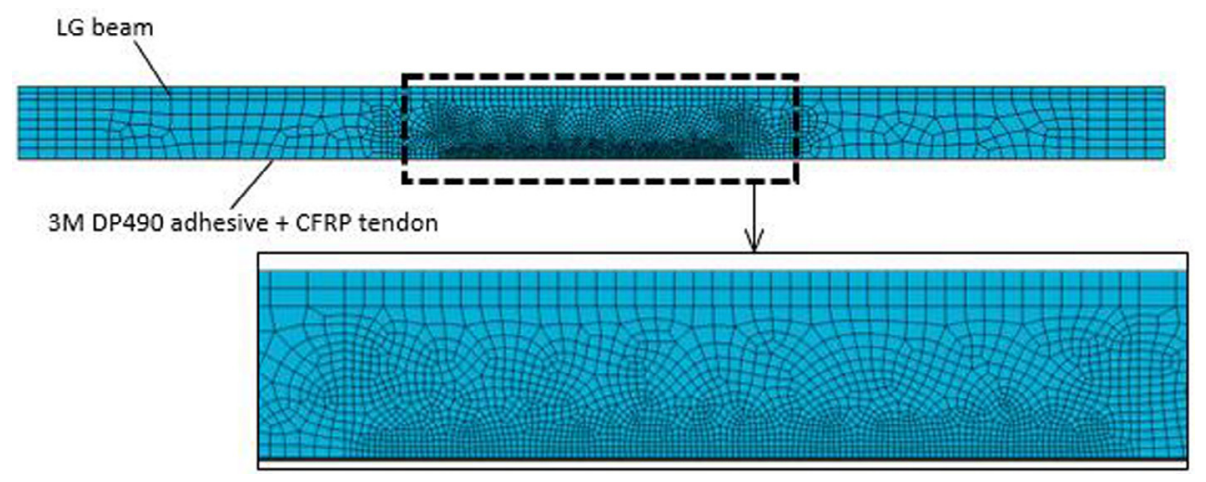

Fig. 3. Reference FE model for glass-CFRP post-tensioned beams, front view and mesh detail (ABAQUS).

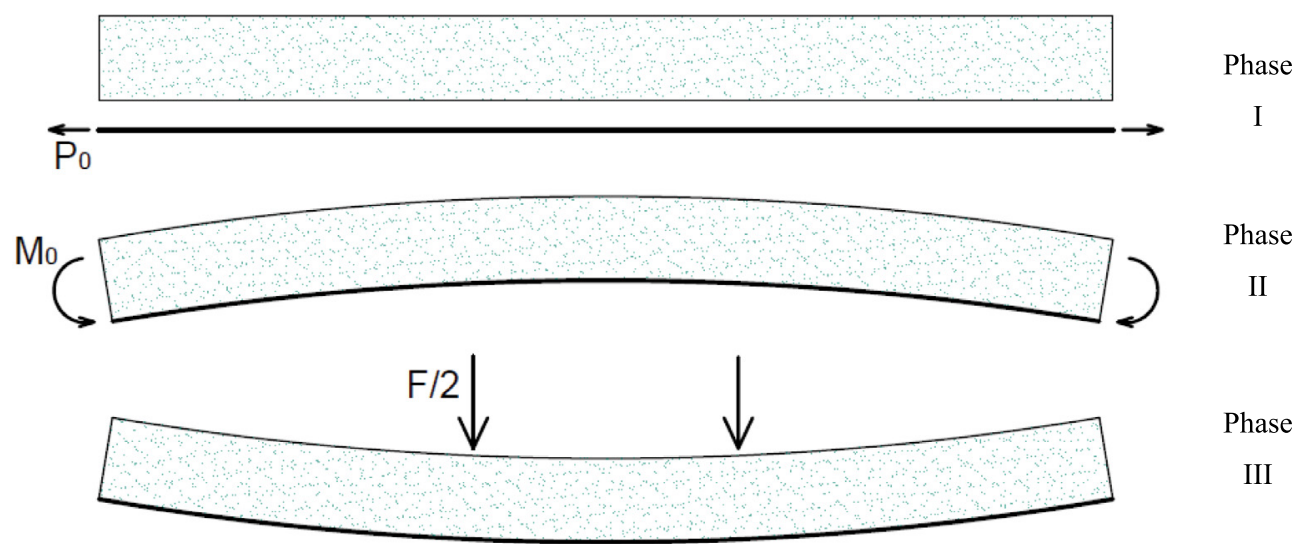

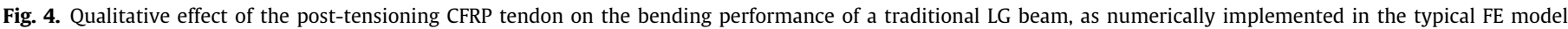
(ABAQUS).

exhibit its benefits in the form of an imposed upward bending for the above LG beam, together with a corresponding bi-triangular distribution of initial stresses in the glass layers leading to an enhanced flexural performance.

\subsubsection{Bending analysis}

The four-point bending simulation was finally carried out (Fig. 4, phase III) on the post-tensioned composite system. The adhesively bonded CFRP tendon was still simply supported at the ends, in accordance with the experimental setup provided in Fig. 1 as well as with phase II. Additional lateral bracings able to prevent out-of-plane deformations of the LG beam were also taken into account, in the form of nodal restraints, aiming to reproduce the reference test loading protocol.

Vertical displacements were hence assigned at the top edge of the glass layers, in order to reproduce the effect of the assigned bending loads during the original experimental test. The so defined vertical displacements were linearly increased up to a maximum value of $\approx 25 \mathrm{~mm}$, in accordance with the ultimate vertical deflection experimentally observed for the full-scale test specimens (see for example the FE predictions of the reference M0 model recalled in Fig. 2(a)).

As far as the imposed deflection was increased through each displacement-controlled simulation, FE results were continuously monitored by giving attention to several aspects, including the evolution of maximum reaction forces at the beam supports, the distribution of principal stresses in all the FE model components as well as the possible occurrence and/or propagation of damage in glass, CFRP or adhesive members.

\section{FE sensitivity study and parametric analyses}

An extended FE investigation was hence carried out, aiming to better explore the structural performance of the examined hybrid solution as well as to assess the effects of several input parameters, including both geometrical and mechanical aspects.

In this study, careful consideration was paid especially for some basic aspects, namely (i) the level of initial force in the CFRP tendon $P_{0}$, (ii) the resisting section of the CFRP tendon (i.e. nominal thickness), giving then evidence of the observed overall bending performance as well as of the damage evolution in the post-failure stage, including qualitative propagation of cracks in glass and amount of maximum stresses in the adhesive joint.

\subsection{Initial pre-stressing force in the CFRP tendon}

At a first stage, given the geometrical properties of the reference M0 model, the effects of a different level of initial pre-stressing force $P_{0}$ for the CFRP tendon was explored.

The so obtained FE results are compared in Fig. 5 and Table 2, where the main features of each FE configuration are collected together with the corresponding bending parameters.

For each one of them, the stress ratio is also provided, being:

$R_{\sigma 0}=\frac{\sigma_{0}}{\sigma_{u}}=\frac{\frac{P_{0}}{A_{C F R P}}}{\sigma_{u}}$

where $\sigma_{0}=f\left(P_{0}, A_{C F R P}\right)$ denotes the initial strain, $E_{C F R P}$ the modulus of elasticity, $A_{C F R P}$ the resisting section and $\sigma_{u}=2550 \mathrm{MPa}$ the tensile resistance of the tendon (nominal value, see Table 1 ). 


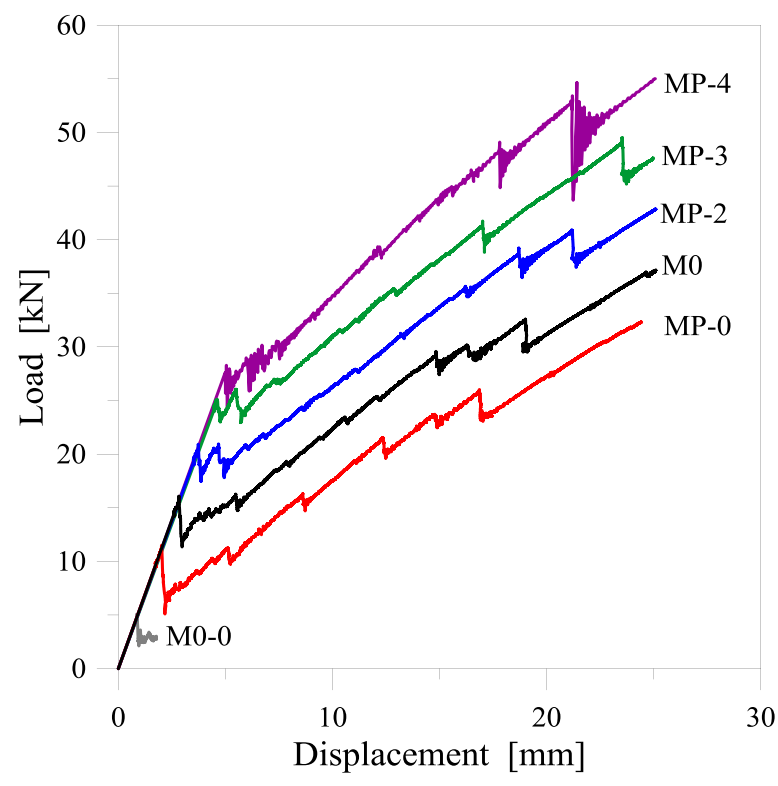

Fig. 5. Load-deflection response of glass-CFRP post-tensioned beams, by changing the level of initial pre-stressing force $P_{0}$.

In Table 2, the corresponding initial strain is also given for each beam, being

$R_{\varepsilon 0}=\frac{\varepsilon_{0}}{\varepsilon_{u}}=\frac{\frac{P_{0}}{E_{C F R P} A_{C R P P}}}{\varepsilon_{u}}$

and $\varepsilon_{u}=1.7 \%$.

As also highlighted in Fig. 5 and Table 2, through the first set of parametric analyses, FE models with increased $P_{0}$ force were investigated (with up to 2, 3 and 4 times the magnifying factor for $P_{0}$ ), together with an FE model deprived of any pre-stressing force (MP-0) as well as another FE model representative of the LG beam only (M0-0). In the MP-0 configuration, the beneficial contribution of the CFRP tendon takes the form of additional tensile rebar with relatively high ultimate resistance, and in any case provides a certain enhancement to the LG section deprived of the CFRP tendon (M0-0).

As far as a certain initial force $P_{0}$ is also assigned to the same resisting cross-section, a rather linear proportional beneficial effect can be then observed, in terms of post-tensioning initial stresses in glass (see Table 2 and Fig. 6, where $\sigma_{c, 0}$ and $\sigma_{t, 0}$ denote respectively the initial compressive and tensile stresses at the bottom and top edges, with $u_{0}$ being representing the mid-span upward deflection due to $P_{0}$ ), as well as first cracking configuration and post-cracked bending response of the same beams.

In the latter case, Table 2 gives in fact evidence of the beam deflection $u_{1, c}$ and reaction force $F_{1, c}$ at the opening of first cracks in glass, together with the corresponding elastic bending stiffness $K_{e l}$ of the full composite glass-CFRP assembly.

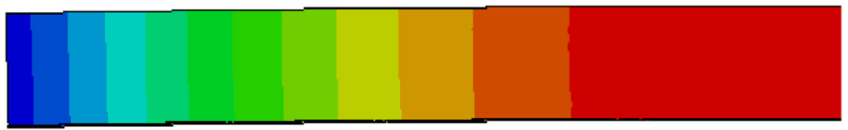

(a)
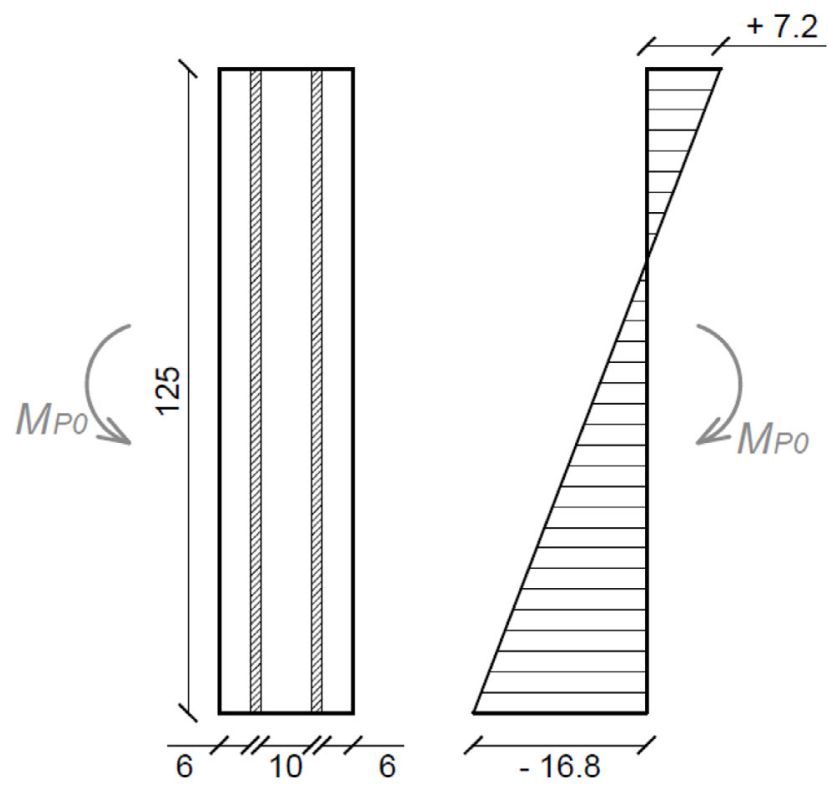

(b)

Fig. 6. Post-tensioning effects on the LG section. (a) upward deflection (front view) and (b) corresponding initial stresses in glass cross-section (example provided for the M0 model, values in $\mathrm{mm}$ and MPa).

\subsection{CFRP tendon section and material properties}

A second set of FE parametric investigations was then carried out by giving attention to the CFRP tendon, aiming to quantify and assess the efficiency of such post-tensioning reinforcement.

In doing so (see Table 3 and Fig. 7(a)), the nominal thickness of the reference CFRP section given in Fig. 1 was first modified, together with the corresponding amount of initial force $P_{0}$.

As far as the reference M0 system was subjected to a $P_{0}$ initial force for the $2 \mathrm{~mm}$ thick CFRP section, comparative calculations were in fact carried out by imposing the same strain level $\varepsilon_{0}$ to all the explored configurations, by taking into account a CFRP tendon with $3 \mathrm{~mm}$ or $4 \mathrm{~mm}$ nominal thickness (MT-3 and MT-4 models). Following Eqs. (4) and (5), the initial stress and strain ratios were hence calculated for the $\mathrm{M}_{i}$ model and compared to the M0 reference values.

As far as the CFRP thickness increases and the corresponding initial stress ratio further increases, marked enhancement of

Table 2

Input parameters for the FE models included in the parametric study, by changing the initial pre-stressing level in the CFRP tendon.

\begin{tabular}{|c|c|c|c|c|c|c|c|c|c|c|}
\hline \multirow[t]{2}{*}{ FE Model \# } & \multicolumn{4}{|c|}{ Model properties } & \multicolumn{3}{|c|}{ Post-tensioning phase } & \multicolumn{3}{|c|}{ Bending stage } \\
\hline & $\begin{array}{l}t_{C F R P} \\
{[\mathrm{~mm}]}\end{array}$ & Initial force & $\begin{array}{l}R_{\sigma 0} \\
(\text { Eq. (4)) }\end{array}$ & $\begin{array}{l}R_{\varepsilon 0} \\
\text { (Eq. (5)) }\end{array}$ & $\begin{array}{l}u_{0} \\
{[\mathrm{~mm}]}\end{array}$ & $\begin{array}{l}\sigma_{c, 0} \\
{[\mathrm{MPa}]}\end{array}$ & $\begin{array}{l}\sigma_{t, 0} \\
{[\mathrm{MPa}]}\end{array}$ & $\begin{array}{l}F_{1, c} \\
{[\mathrm{kN}]}\end{array}$ & $\begin{array}{l}u_{1, c} \\
{[\mathrm{~mm}]}\end{array}$ & $\begin{array}{l}K_{e l} \\
{[\mathrm{kN} / \mathrm{mm}]}\end{array}$ \\
\hline M0 & 2 & $P_{0}$ & 0.118 & 0.126 & 0.7 & 16.8 & 7.2 & 16.6 & 2.95 & 5.62 \\
\hline M0-0 & - & - & - & - & - & - & - & 6.1 & 1.10 & 5.47 \\
\hline MP-0 & 2 & 0 & 0 & 0 & 0 & 0 & 0 & 11.1 & 2.02 & 5.51 \\
\hline MP-2 & 2 & $2 P_{0}$ & 0.235 & 0.252 & 1.4 & 33.8 & 14.3 & 20.8 & 3.73 & 5.57 \\
\hline MP-3 & 2 & $3 P_{0}$ & 0.353 & 0.378 & 2.2 & 50.5 & 21.4 & 24.8 & 4.64 & 5.34 \\
\hline MP-4 & 2 & $4 P_{0}$ & 0.471 & 0.504 & 2.5 & 53.7 & 25.0 & 27.7 & 4.95 & 5.59 \\
\hline
\end{tabular}


Table 3

Input parameters for the FE models included in the parametric study, by changing the CFRP tendon thickness, initial strain and material.

\begin{tabular}{|c|c|c|c|c|c|c|c|c|c|c|}
\hline \multirow[t]{2}{*}{ FE Model \# } & \multicolumn{4}{|c|}{ Model properties } & \multicolumn{3}{|c|}{ Post-tensioning phase } & \multicolumn{3}{|c|}{ Bending stage } \\
\hline & $\begin{array}{l}t_{\text {CFRP }} \\
{[\mathrm{mm}]}\end{array}$ & Initial force & $\begin{array}{l}R_{\sigma 0} \\
\text { (Eq. (4)) }\end{array}$ & $\begin{array}{l}R_{\varepsilon 0} \\
(\text { Eq. (5)) }\end{array}$ & $\begin{array}{l}u_{0} \\
{[\mathrm{~mm}]}\end{array}$ & $\begin{array}{l}\sigma_{c, 0} \\
{[\mathrm{MPa}]}\end{array}$ & $\begin{array}{l}\sigma_{t, 0} \\
{[\mathrm{MPa}]}\end{array}$ & $\begin{array}{l}F_{1, c} \\
{[\mathrm{kN}]}\end{array}$ & $\begin{array}{l}u_{1, c} \\
{[\mathrm{~mm}]}\end{array}$ & $\begin{array}{l}K_{e l} \\
{[\mathrm{kN} / \mathrm{mm}]}\end{array}$ \\
\hline M0 & 2 & $P_{0}$ & 0.118 & 0.126 & 0.7 & 16.8 & 7.2 & 16.6 & 2.95 & 5.62 \\
\hline MT-3 & 3 & $2.25 P_{0}$ & 0.176 & 0.126 & 1.5 & 35.8 & 15.3 & 22.1 & 3.92 & 5.63 \\
\hline MT-4 & 4 & $4 P_{0}$ & 0.235 & 0.126 & 1.8 & 42.2 & 18.1 & 26.5 & 4.46 & 5.94 \\
\hline MT-3-2 & 3 & $2 P_{0}$ & 0.156 & 0.167 & 1.3 & 31.8 & 13.5 & 21.6 & 3.73 & 5.79 \\
\hline MT-3-2S & 3 steel & $2 P_{0}$ & 0.465 & 0.044 & 1.1 & 28.1 & 11.1 & 19.8 & 3.13 & 6.32 \\
\hline
\end{tabular}

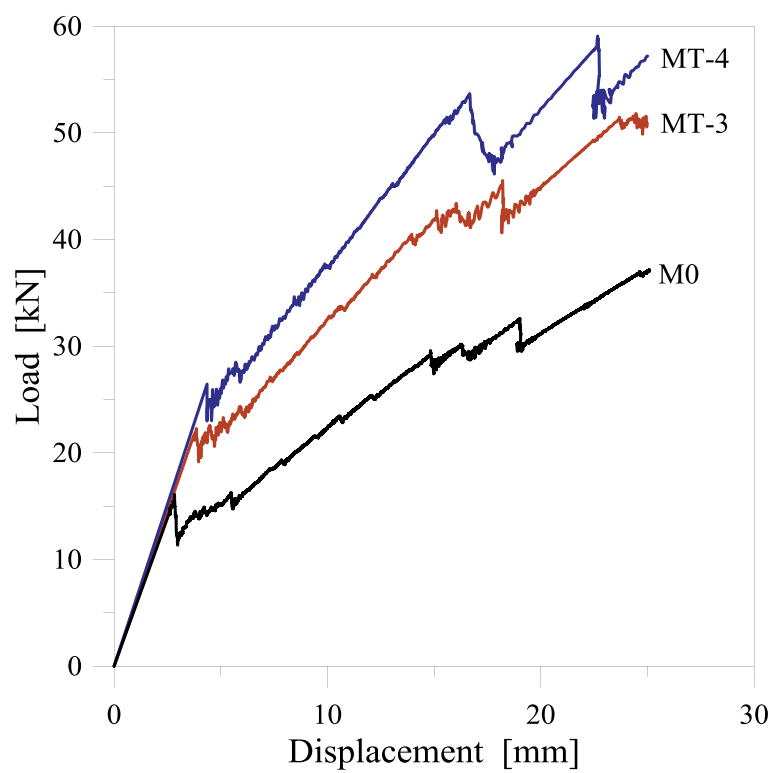

(a)

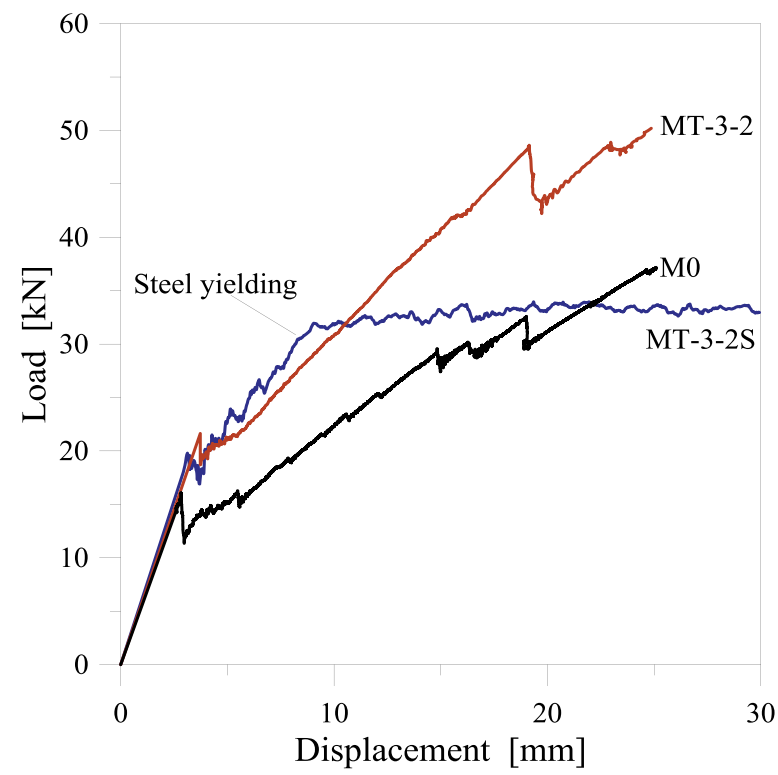

(b)

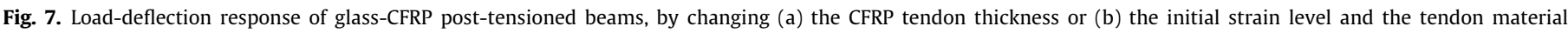
properties.

post-tensioning beneficial effects can be observed. Compared to the M0 configuration, with increased first cracking load and corresponding elastic stiffness for the so assembled sections.

In the same set of FE simulations, additional configurations were also detected by assessing the effects of CFRP material properties.

Due to the implicit tensile brittle nature of CFRP sections, the overall load-deflection response of the examined beam typology presents some key aspects, especially in terms of typical postcracked response.

A rather different bending performance can be observed for example in the case of post-tensioned steel-glass hybrid beams, given the same cross-sectional dimensions and initial prestressing force $P_{0}$ for the tensile tendon. While the structural performance of steel-glass post-tensioned beams has been explored in $[15,26]$, in this paper the bending response of the reference glass-CFRP beams is compared and assessed in Table 3 and Fig. 7 (b) with a FE model having identical cross-section, but a stainless steel tendon replacing the CFRP solid section (see MT-3-2 and MT-3-2S models). To this aim, the CFRP equivalent material was hence replaced in the MT-3-2S model with an elasto-plastic constitutive law, given $E_{\text {steel }}=200 \mathrm{GPa}$ the modulus of elasticity, $\sigma_{y, \text { steel }}=\sigma_{u \text {,steel }}=860 \mathrm{MPa}$ the experimental yielding and ultimate stress $[15,26], v_{\text {steel }}=0.3$ the Poisson ratio and $\varepsilon_{u, \text { steel }}=45 \%$ the nominal ultimate strain [27].

From Fig. 7(b), in particular, it is possible to notice that a rather comparable first cracking response can be observed for the MT-3-2 and MT-3-2S models. As far as the steel section starts to yield, the additional post-cracked resistance potential of the full composite assembly fully vanishes, however, compared to the CFRP reinforced section. Major discrepancies can be indeed also observed in terms of overall ductility of the same beams, where the CFRP model ultimate deflection is strictly related to the tensile brittle behaviour of the pultruded tendon, compared to the steel section which experimentally exhibited a rather stable bending performance up to $\approx 60 \mathrm{~mm}$ of maximum deflection $[15,26]$.

\subsection{Damage propagation and collapse configuration}

As far as in the previous sections the major effects of several geometrical and mechanical aspects were highlighted in terms of post-tensioning initial effects, elastic bending response and fist glass cracking for the examined beam configurations, careful consideration was finally paid to the assessment of damage propagation in each beam component, as well as to the expected collapse mechanism for the same beams. Additional comparative calculations were hence carried out by monitoring:

a) the qualitative distribution of cracks in the glass layers

b) the amount of maximum compressive stresses in the glass layers

c) the evolution of shear stresses in the adhesive joint

d) the amount of maximum principal stresses in the CFRP tendon 
Some of the so obtained (a)-(d) results are compared in Table 4 for all the $M_{i}$ models previously discussed, while Fig. 8 shows a selection of cracks distribution in glass for the MO model and Fig. 9 presents the evolution of maximum stresses in the posttensioning tendon as well as in the adhesive joint (for some selected FE models only).

In terms of qualitative glass cracking and damage propagation, a distribution of tensile fractures rather in close correlation with Fig. 2 was observed for all the examined FE models, hence suggesting a stable bending performance for the investigated structural typology.

In this regard, Fig. 8 presents the distribution of tensile fractures in the full LG section as well as in each separate glass layer, as obtained for the M0 model at several amplitudes of maximum deflection. As shown, a rather stable propagation of fracture was observed through the thickness of the LG section, with partial un-symmetrical distribution of cracks occurring at large deflections only, i.e. in severely damaged beams (see Fig. 8(b)).

Despite an apparently stable overall performance of the explored FE beams in the post-cracked stage, important variations were indeed observed in terms of distribution of stresses in each FE model as well as in terms of expected failure mechanism.

In Table 4, in this regard, some further key output results are provided both at first glass cracking as well as in the bending configuration of maximum imposed deflection. In this research paper, based on experimental tests and preliminary FE results recalled for

Table 4

Stress evolution and comparative results for each FE model component.

\begin{tabular}{|c|c|c|c|c|c|c|c|c|c|c|c|c|}
\hline \multirow[t]{2}{*}{$\begin{array}{l}\text { FE } \\
\text { Model \# }\end{array}$} & \multicolumn{3}{|c|}{ First glass cracking } & \multicolumn{8}{|c|}{$\begin{array}{l}\text { Ultimate bending stage } \\
\left(u_{\max }=25 \mathrm{~mm}\right)\end{array}$} & \multirow[t]{2}{*}{ Expected debonding } \\
\hline & $\begin{array}{l}\sigma_{c, 1} \\
{[\mathrm{MPa}]}\end{array}$ & $\begin{array}{l}\sigma_{C F R P, 1} \\
{[\mathrm{MPa}]}\end{array}$ & $\begin{array}{l}R \sigma_{1} \\
(\text { Eq. (4)) }\end{array}$ & $\begin{array}{l}F_{\max } \\
{[\mathrm{kN}]}\end{array}$ & $\begin{array}{l}\Delta F \\
{[\%](\text { Eq. }(6))}\end{array}$ & $\begin{array}{l}\sigma_{c, \max } \\
{[\mathrm{MPa}]}\end{array}$ & $\begin{array}{l}R \sigma, \max \\
(\text { Eq. (4)) }\end{array}$ & $\begin{array}{l}R \varepsilon, \max \\
(\text { Eq. }(5))\end{array}$ & $\begin{array}{l}\tau \max \\
{[\mathrm{MPa}]}\end{array}$ & $\begin{array}{l}\tau_{\text {mid }} \\
{[\mathrm{MPa}]}\end{array}$ & $\begin{array}{l}\tau_{\text {supp }} \\
{[\mathrm{MPa}]}\end{array}$ & \\
\hline M0 & 51.1 & 536.1 & 0.210 & 35.2 & 112 & 284.2 & 0.584 & 0.494 & 55.7 & 13.2 & 20.3 & yes \\
\hline MO-0 & 23.2 & - & - & 6.1 & 0 & 23.2 & - & - & - & - & - & - \\
\hline MP-0 & 47.4 & 247.0 & 0.097 & 32.6 & 193 & 265.2 & 0.519 & 0.553 & 60.7 & 2.2 & 16.1 & yes \\
\hline MP-2 & 64.5 & 771.3 & 0.302 & 42.8 & 106 & 297.7 & 0.699 & 0.497 & 63.1 & 2.6 & 16.3 & yes \\
\hline MP-3 & 71.4 & 1093.1 & 0.429 & 47.8 & 129 & 303.9 & 0.809 & 0.498 & 121.4 & 10.1 & 6.2 & yes \\
\hline MP-4 & 80.3 & 932.6 & 0.366 & 54.9 & 98 & 335.8 & 0.948 & 0.445 & 108.9 & 5.9 & 12.6 & yes \\
\hline MT-3 & 62.1 & 581.0 & 0.227 & 51.3 & 132 & 358.7 & 0.559 & 0.603 & 98.4 & 6.2 & 27.3 & yes \\
\hline MT-4 & 80.2 & 576.4 & 0.226 & 57.9 & 118 & 410.3 & 0.502 & 0.353 & 102.3 & 4.2 & 12.3 & yes \\
\hline MT-3-2 & 68.5 & 594.9 & 0.233 & 50.2 & 132 & 366.8 & 0.553 & 0.593 & 88.9 & 10.2 & 26.7 & yes \\
\hline MT-3-2S & 56.5 & 496.6 & 0.578 & 35.9 & 81 & 237.3 & $1 \mathrm{Y}^{*}$ & $0.105^{*}$ & 41.2 & 8.7 & 19.2 & yes \\
\hline
\end{tabular}

$\mathrm{Y}=$ steel yielding.

$R_{\max }$ ratios calculated as a function of ultimate stress and strain for stainless steel.

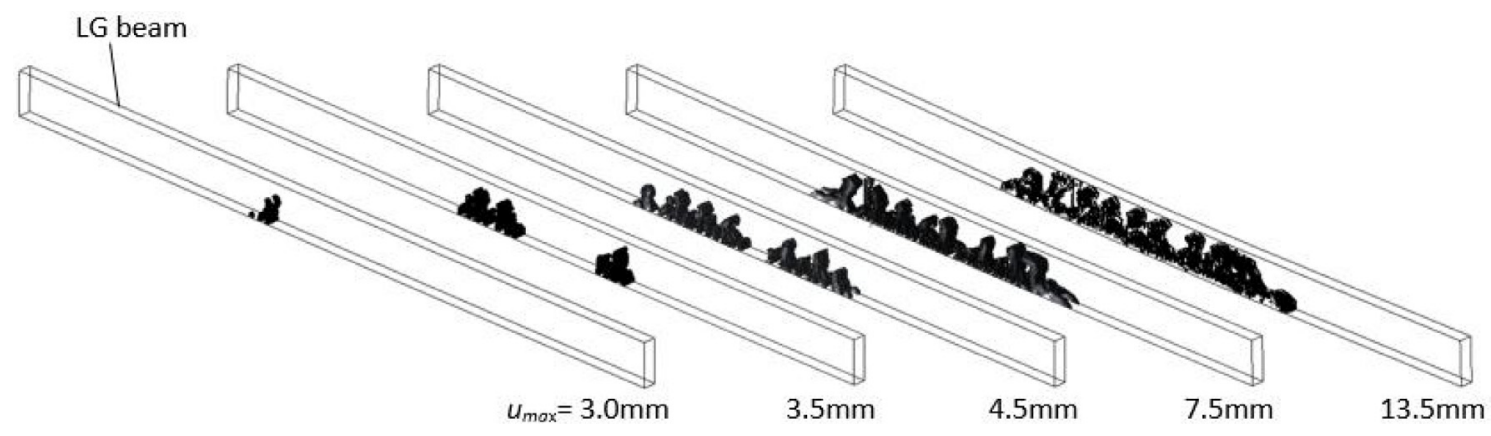

(a)

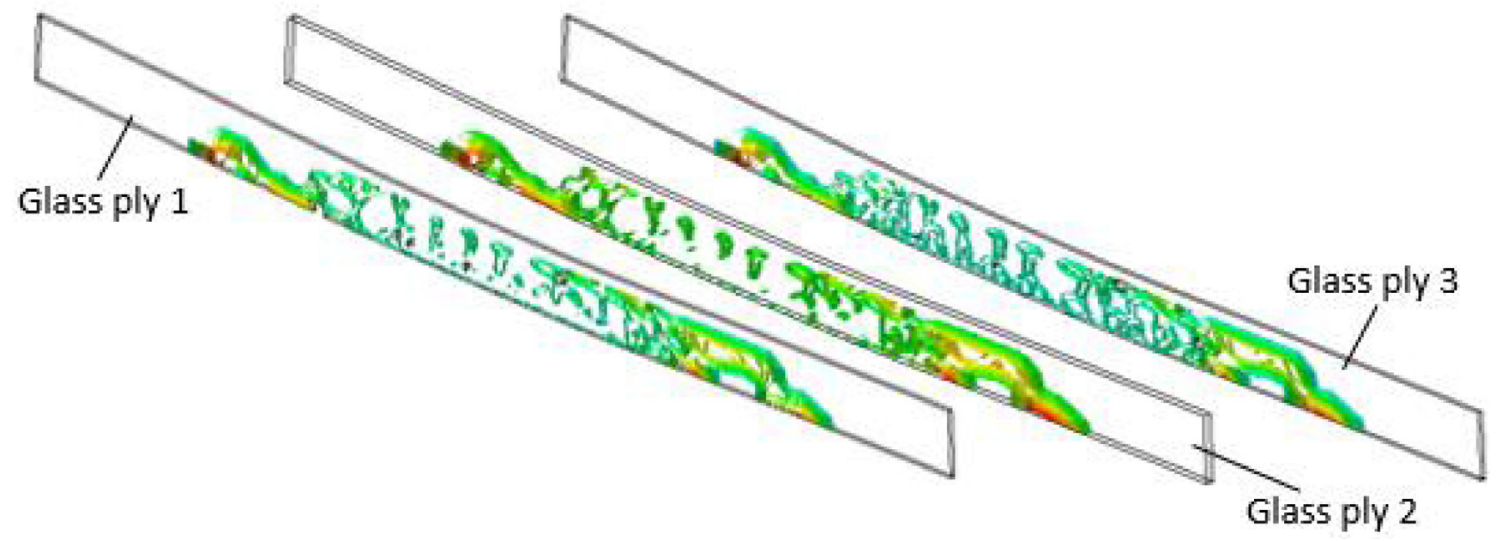

(b) $u_{\max }=25 \mathrm{~mm}$

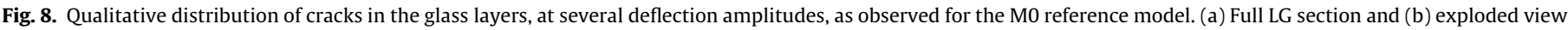
of separate glass foils. 


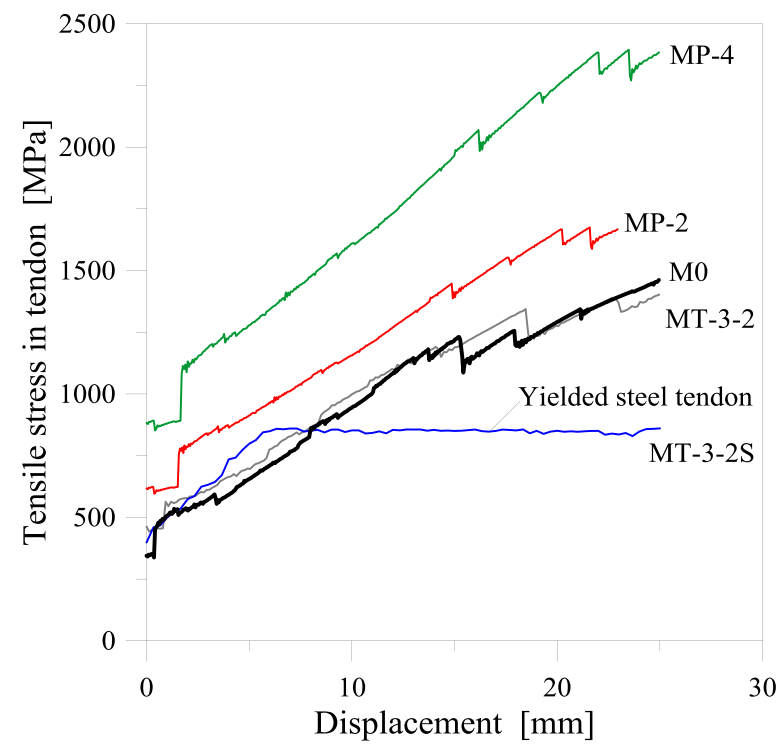

(a)

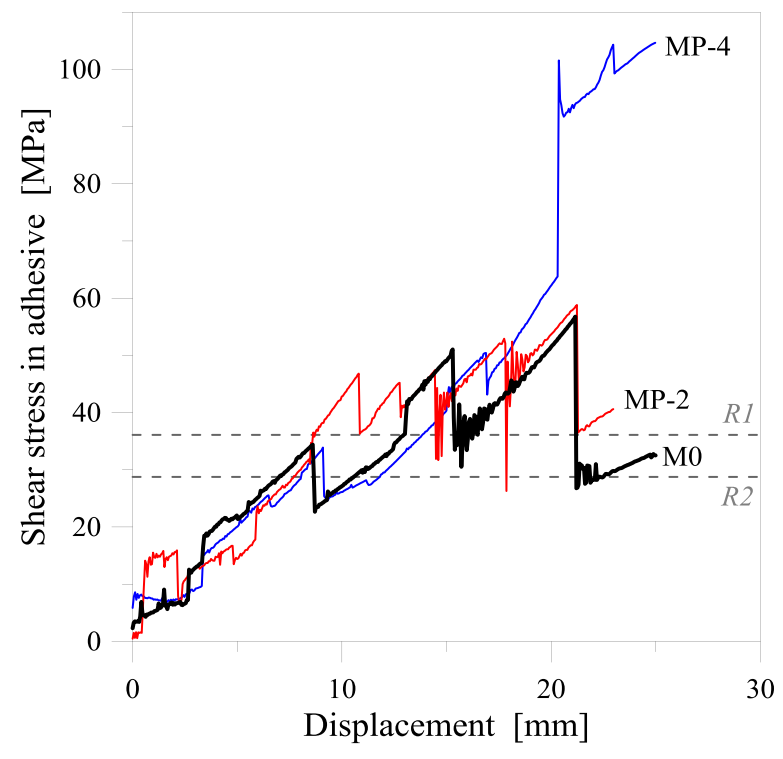

(b)

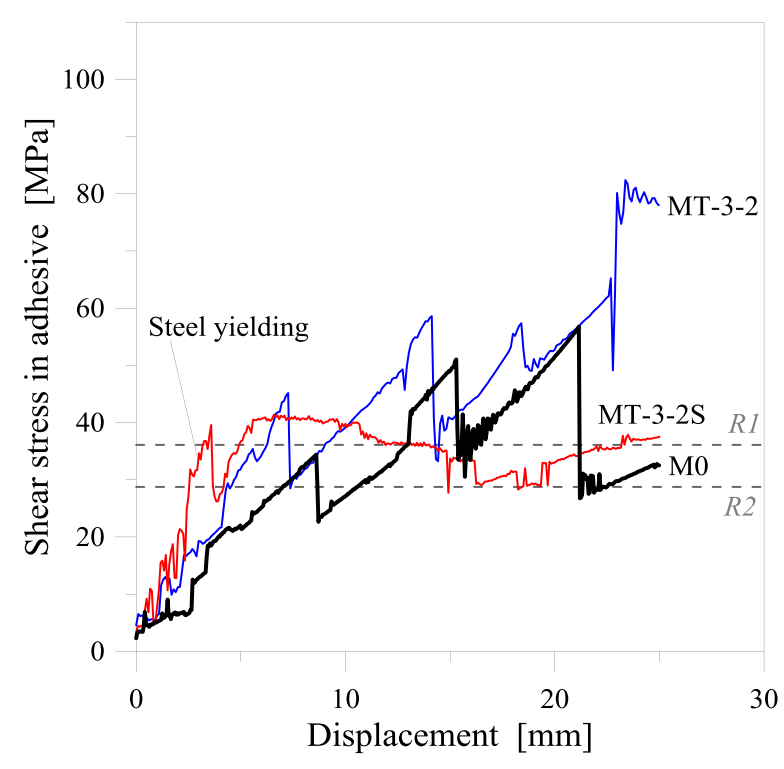

(c)

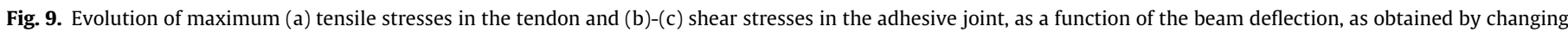
the initial pre-stressing force or the tendon geometrical and mechanical tendon properties.

the M0 reference beams (where collapse was experimentally observed at a deflection $u_{\max } \approx 25 \mathrm{~mm}$ ), the latter displacement amplitude was in fact taken into account as reference configuration for an assessment of the bending behaviour of all the $\mathrm{M}_{i}$ models. The ultimate bending responses compared in Table 4, in this sense, do not represent the expected collapse configuration for all the $\mathrm{M}_{i}$ beams, but can offer - especially in lack of additional mechanical parameters for the calibration of materials and mechanical interactions - interesting points of analysis and discussion.

In Table $4, \sigma_{c, 1}$ denotes the maximum compressive stress in glass at first cracking and maximum imposed deflection, while $\sigma_{C F R P, 1}$ is the maximum tensile stress in the tendon and $R \sigma_{1}$ is calculated in accordance with Eq. (4), being representative of the stress ratio in the tendon at the opening of first cracks in glass. In terms of 'ultimate' bending condition, $F_{\max }=f(25 \mathrm{~mm})$ is the reaction force taken up by each beam, with
$\Delta F=100 \cdot \frac{F_{\max }-F_{1, c}}{F_{1, c}}$

while $\sigma_{c, \max }$ denotes the compressive stress (maximum envelope) monitored in the glass layers.

The stress and strain ratios $R \sigma_{\text {,max }}$ and $R \varepsilon_{\text {,max }}$, following Eqs. (4) and (5), are hence calculated for the CFRP tendon on the base of the actual tensile stress and strain calculated in its solid section (maximum envelope along the beam span). $\tau_{\text {max }}, \tau_{\text {mid }}$ and $\tau_{\text {supp }}$, finally, represent the corresponding shear stress values in the adhesive joint, as obtained by calculating the maximum envelope over the beam length as well as monitoring the stresses themselves in two key section of the joint (i.e. mid-span section and close to the beam supports, respectively).

Regarding Fig. 9, in accordance with Table 4, the evolution of maximum tensile stresses in the CFRP tendon and shear stresses 
in the adhesive joint are proposed, as a function of the mid-span deflection, for some selected FE models only.

The so collected shear stress values are compared with R1 and R2 reference stresses, being representative of the nominal [22] and experimental [28] ultimate shear resistance for DP490 epoxy joints. Given the same adhesive type, in particular, the R1 value reflects the ultimate shear stress in the case the adherend consists of CFRP components, while the average $\mathrm{R} 2$ value was experimentally calculated by Belis et al. [28] for glass-to-aluminium adhesive connections.

In this regard, it is important to observe that a rather linear correlation was noticed between the imposed deflections and the increase of shear stresses in the adhesive joint, for all the examined beam configurations. Maximum stress values were also generally found to be markedly high, compared to the R1 and R2 reference resistance values, hence suggesting a possible debonding phenomena at the interface between the joint and the LG beam. These maximum stress values were also noticed, however, to have an almost local distribution over the beam span, and in particular to occur in few LG cross-sections only affected by major tensile cracks and material stiffness degradation. To this aim, Table 4 presents in fact shear stresses $\tau_{\text {mid }}$ and $\tau_{\text {supp }}$ in the same adhesive joints that are indeed significantly lower than the R1, R2 and $\tau_{\max }$ corresponding values. In this sense, it is expected that possible debonding effects could have minor effects on the actually observed FE predictions. At the current stage of the research study and based on the potential of the implemented FE models, giving evidence that additional experimental and FE investigations should be dedicated to the assessment of specific aspects such as debonding or creep phenomena for the explored beam typology, it can be also pointed out that the actual capacity of adhesive joints to provide a rather stable and almost rigid connection between the CFRP tendon and the upper LG beam should be verified in a large deflection stage, being these latter configurations typically associated to severe damage in each beam component.

In terms of overall structural effects due to the pre-stressed CFRP tendon, as also observed in [19] for another post-tensioned beam typology, an optimal range of pre-stressing force can be generally found for these systems. From Table 4, for example, it can be noticed that as far as the initial pre-stressing force $P_{0}$ is such that the stress ratio $R \sigma_{0}$ exceeds a limit value of $\approx 0.5$, enhanced initial effects due to post-tensioning only are obtained (compared to the MP-0 or M0-0 beams deprived of pre-stressing force and tendon), but premature tensile failure in the CFRP tendon is also expected (see for example the comparative results provided for the MP-4 system). Maximum compressive stresses in glass, typically achieved close to the top edge of glass close to mid-span, were generally found to lie in the order of $\approx 250-300 \mathrm{MPa}$, with maximum values up to $\approx 410 \mathrm{MPa}$ for the beams with increased CFRP section (MT-3 and MT-4 beams). In this sense, the maximum compressive stresses in glass were found to be typically lower than the corresponding nominal resistance of the material, namely in the order of $\approx 1000 \mathrm{MPa}$, as well as in agreement with other numerical research investigation on similar structural glass beams (see for example $[11,14]$ ).

A totally different bending performance can be observed as far as the CFRP tendon is replaced with a stainless steel section (see MT-3-2S model). In the latter case, compared to the MT-3-2 beam with CFRP solid section, premature yielding of the steel tendon manifests in the form of lower ultimate resistance $F_{\max }$, despite the implicit ductility and large ultimate strain of steel, as emphasized by the $\Delta F, R \sigma_{\text {,max }}$ and $R_{\sigma, \max }$ values of Table 4 .

\section{Conclusions}

In this paper, a short recapitulation of existing glass-FRP beam systems has been provided. Moreover, the bending performance of a selected post-tensioned glass-CFRP composite beam solution has been numerically investigated via Finite-Element numerical models.

Based on past experimental and numerical literature contributions, the effects of various mechanical and geometrical aspects has been assessed via a sensitivity study for the examined beam typology.

In particular, variations in initial pre-stressing force and/or geometrical and mechanical properties of the CFRP tendon have been numerically explored, compared to the reference beams. Postprocessing of FE results, including first cracking configuration as well as damage propagation and evolution in each beam component has been hence discussed, aiming to further explore the specific design concept.

\section{References}

[1] Martens K, Caspeele R, Belis J. Development of composite glass beams - a review. Eng Struct 2015;101:1-15.

[2] Martens K, Caspeele R, Belis J. Development of reinforced and post-tensioned glass beams: review of experimental research. J Struct Eng 2015;142 (5):04015173.

[3] Palumbo M, Palumbo D, Mazzucchelli M. A new roof for the XIIIth century "Loggia de Vicari" (Arquà Petrarca - PD - Italy) based on structural glass trusses: a case study. In: Proceedings of Glass Processing Days; 2005, p.1-3

[4] Correia JR, Valarinho L, Branco FA. Post-cracking strength and ductility of glassGFRP composite beams. Compos Struct 2011:93:2299-309.

[5] Valarinho L, Correia JR, Branco FA. Experimental study on the flexural behaviour of multi-span transparent glass-GFRP composite beams. Constr Build Mater 2013;49:1041-53.

[6] Louter C, Leung C, Kolstein H, Vamberský J. Structural glass beams with embedded glass fibre reinforcement. Proceedings of challenging glass 2 conference on architectural and structural applications of glass. TU Delft; 2010.

[7] Speranzini E, Agnetti S. Flexural performance of hybrid beams made of glass and pultruded GFRP. Constr Build Mater 2015;94:249-62.

[8] Speranzini E, Neri P. Structural behavior of reinforced glass. Proceedings of Glass Performance Days; 2009. p. 355-60.

[9] Pascual C, Montali J, Overend M. Adhesively-bonded GFRP-glass sandwich components for structurally efficient glazing applications. Compos Struct 2017;160:560-73.

[10] Louter C, Cupać J, Débonnaire M. Structural glass beams prestressed by externally bonded tendons. In: Proceedings of GlassCon global conference, July 7-10, Philadelphia, PA, USA (USB drive); 2014.

[11] Bedon C, Louter C. Finite-Element numerical simulation of the bending performance of post-tensioned structural glass beams with adhesively bonded CFRP tendons. Am J Eng Appl Sci 2016;9(3):680-91.

[12] Simulia. ABAQUS v. 6.12 computer software and online documentation, Dassault Systems, Providence, RI, USA; 2012.

[13] Louter C, Nielsen JH. Numerical analyses of the effect of SG-interlayer shear stiffness on the structural performance of reinforced glass beams. In: Proceedings of COST action TU0905 Mid-term conference on structural glass; 2013. p. 405-11, ISBN 978-1-138-00044-5.

[14] Bedon C, Louter C. Exploratory numerical analysis of SG-laminated reinforced glass beam experiments. Eng Struct 2014;75:457-68.

[15] Bedon C, Louter C. Finite Element analysis of post-tensioned SG-laminated glass beams with adhesively bonded steel tendons. Compos Struct 2017; $167: 238-50$.

[16] Nielsen JH, Olesen JF. Post-crack capacity of mechanically reinforced glass beams (MRGB). Proceedings of fracture mechanics of concrete and concrete structures - recent advances in fracture mechanics of concrete. Seoul: Korea Concrete Institute; 2010. ISBN 978-89-5706-160-6.

[17] Martens K, Caspeele R, Belis J. Numerical investigation of two-sided reinforced laminated glass beams in statically indeterminate systems. Glass Struct Eng 2016;1(1):417-31. http://dx.doi.org/10.1007/s40940-016-0005-6.

[18] Kozlowski M, Kadela M, Hulimka J. Numerical investigation of structural behaviour of timber-glass composite beams. Procedia Eng 2016;161:990-1000.

[19] Bedon C, Louter C. Finite-Element analysis of post-tensioned SG-laminated glass beams with mechanically anchored tendons. Glass Struct Eng 2016;1 (1):19-37. http://dx.doi.org/10.1007/s40940-0167.

[20] Neto P, Alfaiate J, Valarinho L, Correia JR, Branco FA, Vinagre J. Glass beams reinforced with GFRP laminates: experimental tests and numerical modelling using a discrete strong continuity approach. Eng Struct 2015;99:253-63.

[21] M Scotch-WeldTM. EXP ${ }^{\mathrm{TM}}$ Adhesive DP490, Product Data Sheet; 1996.

[22] Torayca. T700 Technical Data Sheet No. CFA-005; 2008.

[23] EN 572-2. Glass in buildings-basic soda lime silicate glass products. CEN, Brussels, Belgium; 2004.

[24] Santarsiero M, Louter C, Nussbaumer A. The mechanical behaviour of SentryGlas $^{\circledR}$ ionomer and TSSA silicon bulk materials at different temperatures and strain rates under uniaxial tensile stress state. Glass Struct Eng 2016. http://dx.doi.org/10.1007/s40940-016-0018-1. 
[25] Nhamoinesu S, Overend M. The mechanical performance of adhesives for a steel-glass composite façade system. Proceedings of challenging glass $3-$ conference on architectural and structural applications of glass. TU Delft; 2012.

[26] Louter C, Cupać J, Lebet JP. Exploratory experimental investigations on posttensioned structural glass beams. J Façade Des Eng 2014;2:3-18.

[27] EN 1993-1-4. Eurocode 3-design of steel structures - part 1-4: general rules Supplementary rules for stainless steels; 2006

[28] Belis J, Van Hulle A, Out B, Bos F, Callewaert D, Poulis H. Broad screening of adhesives for glass-metal bonds. In: Proceedings of Glass Performance Days; 2011. p. 286-7 